\title{
Progressive Shortening of the Periodic Breathing Cycle Duration in Normal Infants
}

\author{
KEITH J. BARRINGTON, NEIL N. FINER, AND MALCOLM H. WILKINSON \\ Department of Newborn Medicine, Royal Alexandra Hospital, the Department of Pediatrics, University of \\ Alberta, Edmonton, Alberta, and the Faculty of Medicine, University of Calgary, Calgary, Alberta, Canada
}

\begin{abstract}
Ten normal full-term neonates were monitored by oxycardiorespirography in hospital during the 1st wk of life, and subsequently at home at 4,8 , and 12 wk of age in a longitudinal study of the duration of the periodic breathing cycle during spontaneous sleep. Periodic breathing was observed in 25 of the 40 studies, with a total of 168 epochs of periodicity noted. Eighty-four percent of the periodic epochs occurring during nonrapid eye movements were preceded by a sigh, body movements, or sleep state transition, compared with $41 \%$ during rapid eye movements $(p<0.005)$. There was a progressive reduction in the periodic breathing cycle duration, which fell significantly between the 1st and 4th wk, in both sleep states, $(p<$ 0.001 ). There was a further significant fall between 4 and 12 wk in nonrapid eye movement sleep $(p<0.05)$, and there was no significant difference between sleep states at any postnatal age. The overall change in the duration of the periodic cycle, for both sleep states combined, was from $15.0 \pm 3.6 \mathrm{~s}$ at $<1$ wk to $12.4 \pm 1.8 \mathrm{~s}$ at $12 \mathrm{wk}$ of age. The periodic breathing cycle duration progressively shortens over the first 3 months of life. We postulate that this shortening may be a useful indicator of peripheral chemoreceptor maturation over this time period. (Pediatr Res 21: 247-251, 1987)
\end{abstract}

\section{Abbreviations}

A, apnea duration, during periodic breathing

$B$, breathing duration, during a periodic cycle

$C$, cycle duration of periodic breathing

REM, rapid eye movement

$\mathrm{TcPO}_{2}$, transcutaneous oxygen tension

Premature and full-term neonates are prone to a pattern of breathing in which recurrent short apneas occur at approximately regular intervals, i.e. periodic breathing. The cause of this respiratory pattern is uncertain. Periodicity can be produced in animal models by suppression of the central chemoreceptor $(1,2)$ and is abolished by removal of peripheral chemoreceptor input (1, 2). This suggests that periodicity is dependent on normal peripheral chemoreceptor function and may occur as a result of the following: time delays in the feed-back loop, the relative lack of damping provided by oxygen stores in the lung, and the hyperbolic relationship between decreases in oxygen tension and peripheral chemoreceptor output $(3,4)$.

Received July 21, 1986; accepted October 17, 1986

Correspondence and requests for reprints should be addressed to Neil N. Finer, M.D., Department of Newborn Medicine, Royal Alexandra Hospital, 10240 Kingsway, Edmonton, Alberta, Canada, T5H 3V9.

Supported by a Grant from the MSI Foundation, Edmonton, Alberta, Canada. K.J.B. is the recipient of a Clinical Fellowship of The Alberta Heritage Foundation for Medical Research.
Many investigators have reported the proportion of time which newborn infants spend in periodic breathing (5-8). There has, however, been very little investigation of other features of periodic breathing, and no studies which have investigated the duration of the individual cycle, i.e. the time from the end of one periodic apnea to the end of the subsequent periodic apnea. The description of these features may be important in understanding the changes in respiratory control which are occurring during early infancy.

In the newborn lamb during postnatal maturation, a progressive shortening in the time required for the carotid chemoreceptor to respond to a change in arterial oxygen tension has been demonstrated (9). We hypothesized that a reduction in the chemoreceptor response time should lead to a progressive shortening in the duration of the periodic cycle in normal newborn infants during the first 3 months of postnatal life.

\section{MATERIALS AND METHODS}

Ten infants, delivered at the Royal Alexandra Women's Hospital, between 37 and 41 wk gestational age, birth weight appropriate for gestational age, without perinatal asphyxia or other pre- or perinatal complications, whose mothers were nonsmokers and resident within a 30 mile radius of Edmonton, were studied following informed parental consent. Infants were studied in the hospital within the first 7 days of life and subsequently at home at 4,8 , and 12 wk of age. In order to ensure that sleep was as normal as possible, all studies were performed during spontaneous sleep, without prior sleep deprivation. The recordings were produced during a single sleep episode, being terminated when more than brief arousal was noted, thus limiting the duration of the studies, particularly the study performed during the 1st postnatal wk.

The inhospital studies were performed in the Neonatal Research Laboratory, during a daytime nap, after a feed, for a minimum of $3 \mathrm{~h}$. The infants were placed on an overhead servocontrolled radiant warmer, and their heart rate and impedance pneumography were monitored using a neonatal cardiorespirograph (model 78801A, Hewlett Packard, Waltham MA). Endtidal carbon dioxide was recorded in order to monitor nasal airflow using an infra-red carbon dioxide analyzer (model LB-2, Beckman Instruments Inc., Schiller Park, IL) with the catheter taped at the orifice of one nostril. Transcutaneous oxygen tension $\left(\mathrm{TcPO}_{2}\right.$, Roche model 631, Roche Medical Electronics, Cranbury, $\mathrm{NJ}$ ) was continuously monitored throughout by means of an electrode placed on the anterior trunk with a probe temperature of $43.5^{\circ} \mathrm{C}$. The electrooculogram was recorded on a single channel using five electrodes placed around the eye (HewlettPackard model 8811A). All of the above data were continuously recorded on an eight channel polygraph.

The three subsequent recordings, performed in the infant's own home during the evening and night, were carried out for a minimum of $5 \mathrm{~h}$ using a Roche model 335 oxycardiorespiro- 
graph, which records heart rate, impedance pneumogram, and $\mathrm{TcPO}_{2}$. During all studies a trained research nurse was continuously in attendance. Sleep state was classified according to clinical observation by the nurse, utilizing behavioral criteria (10). NonREM sleep was recognized when the eyes were firmly closed and still, with no motor activity other than occasional myoclonic jerks. REM sleep was characterized by eyes which were usually closed although brief eye opening could occur, and REM were usually present, associated with a wide range of motor activity. Sleep periods which could not be clearly classified into REM or non-REM were recorded as indeterminate. Data from indeterminate sleep states were eliminated from further analysis. During the inhospital study the electrooculogram was also used as an aid to sleep state definition.

The paper speed of the two recorders is regularly calibrated by running the recorder at an indicated speed for a given interval as timed by a stopwatch and measuring the paper generated during this interval. The paper speed has remained consistently within $1 \mathrm{~s}$ of expected in $10 \mathrm{~min}$. Repeated evaluation of our methodology has demonstrated that time intervals of $0.5 \mathrm{~s}$ are readily discriminated, with minimal interobserver variability. Fifty percent of the recordings were analyzed by two technicians, one of whom was blinded as to the infant and the study age.

Apnea was defined, in the laboratory study, as an absence of nasal airflow (end-tidal carbon dioxide) of greater than or equal to $2 \mathrm{~s}$; apneas were further subclassified as being central or obstructive dependent on the presence or absence of continuing respiratory efforts, as recorded by the impedance pneumogram. Mixed apneas were included with obstructive apneas for further analysis. During the home study, apnea was defined by the absence of respiratory movements on the impedance pneumogram of at least $2 \mathrm{~s}$ and was not further subclassified.

There is no generally accepted definition of periodic breathing, with some investigators accepting regular variations in tidal volume without apnea (5), and others requiring apneas of greater than $3 \mathrm{~s}$ (11). In order to ensure that the ascertainment of periodicity was as objective as possible, and so as not to prejudice the results with regard to cycle duration by requiring an apnea that was too long, we required the presence of 2-s apneas similar to Waite and Thoman (6) and Carse et al. (8). Periodic breathing was, therefore, defined as the occurrence of three or more episodes of apnea of at least $2 \mathrm{~s}$ in duration within a 1-min period, separated by periods of regular respiration. Each episode of periodicity was analyzed for the following: total length of periodic epoch; time from last sleep state change; antecedent events (e.g. sigh, deep breathing, gross body movements); $\mathrm{TcPO}_{2}$ change from beginning to end of episode; mean cycle duration (C); mean breathing duration during each cycle (B); mean apnea length during each cycle (A); and breathing to apnea ratio (B/A). A sigh was considered to have occurred if, after a period of regular respiration, a sudden single breath of increased magnitude was noted (Fig. 1). Two or three successive large magnitude breaths in this situation were referred to as "deep breathing" and were thought to represent successive sighs.

Epoch length was defined as the time from the end of the initial apnea to the end of the final apnea, "C" was calculated for at least two and up to 10 cycles from each epoch, and was defined as the time from the initiation of the first breath of one breathing episode to the initiation of the first breath of the next. " $A$ " was defined as the length of time from the end of the last breath of a breathing cycle to the initiation of the next breath. " $B$ " was calculated by subtraction $(C-A)$. The total amount of time spent in each sleep state was also calculated.

Continuous variables are presented as means $\pm 1 \mathrm{SD}$; for clarity, graphs are shown \pm 1 SEM. Statistical analysis consisted of $\chi^{2}$ with Yates' correction for proportions and two-tailed Student's unpaired $t$ test for comparisons between two groups of continuous variables. For the comparison of multiple unbalanced groups, an analysis of variance was performed according to the suggestions of Snedecor and Cochrane (12). Post hoc analysis,

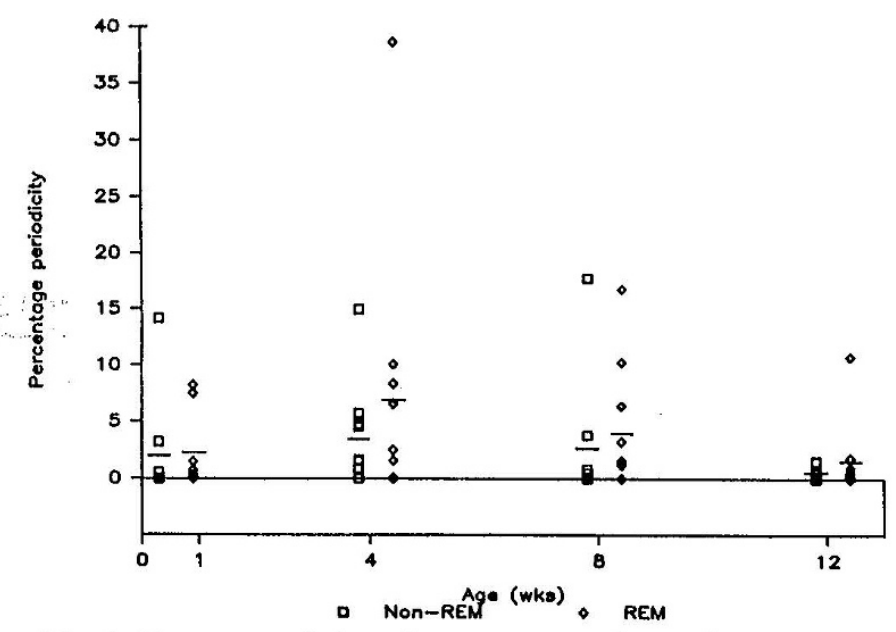

Fig. 1. Percentage of sleep time spent breathing periodically. Each symbol represents a single subject (except for the symbols at the zero line, each of which represents more than one subject). Horizontal lines represent means.

performed if the analysis of variance produced a significant result, consisted of the Studentized Q method, using Satterthwaites rule for assignment of degrees of freedom (11). Because of the marked skew of the periodicity incidence, nonparametric tests (MannWhitney and Friedman analysis of variance) were used to examine these data. A probability level of $<5 \%$ was considered to be significant. The protocol was approved by the Clinical Investigation Committee of the Royal Alexandra Hospital.

\section{RESULTS}

Seven male and three female infants were studied, their mean birth weight was $3.3 \pm 0.3 \mathrm{~kg}$, and their gestational age was 40.5 $\pm 0.8 \mathrm{wk}$. The maternal age was $26.6 \pm 2.6 \mathrm{yr}$; the postnatal age at the time of the first study was $3 \pm 2.6$ days. The mean duration of the first study was $206 \pm 26 \mathrm{~min}$ and of the subsequent studies was $351 \pm 37 \mathrm{~min}$. The correlation coefficient between the results obtained by the two technicians was 0.98 .

The proportion of time during which periodicity was evident varied widely, one infant had no episodes of periodic breathing in any of the studies, while another spent $33.5 \%$ of the second study breathing in a periodic manner. In all, 168 epochs of periodic breathing were analyzed, 131 of which occurred during REM sleep, and 37 during non-REM. Periodicity was noted in six of the 10 studies performed in hospital, in eight of 10 at 4 wk, six of 10 at $8 \mathrm{wk}$, and five of 10 at $12 \mathrm{wk}$ postnatal age.

The percentage of time in each sleep state which was spent breathing periodically increased between the first study and the second, and decreased thereafter (Fig. 1), although these changes were not statistically significant. There was no significant difference in epoch duration or percentage periodicity between REM and non-REM sleep.

Periodic epochs were occasionally triggered by an alteration in sleep state; $11.9 \%$ of the total number of epochs, 20 of 168 , occurred within $15 \mathrm{~s}$ following a sleep state change (Fig. 2). Nineteen percent of the non-REM periodic epochs, seven of 37 , were associated with the transition from REM, compared with $10 \%$ of the REM epochs, 13 of 131 , which were associated with the transition from non-REM, $\chi^{2}{ }_{1}=$ NS.

Sighs preceded $18 \%$ (24 of 131$)$ of periodic epochs during REM and $59 \%$ (22 of 37$)$ of epochs during non-REM $\left(\chi^{2}{ }_{1}=\right.$ $22.53, p<0.005)$ and were commonly associated with a pattern of damped periodic breathing, especially in quiet sleep.

A significantly higher proportion $\left(\chi^{2}{ }_{1}=19.24, p<0.005\right)$ of the periodic epochs which occurred during quiet sleep (84\%, 31 of 37) were provoked by either sleep state change from REM, sighs, or deep breathing. In contrast, a minority of periodic 


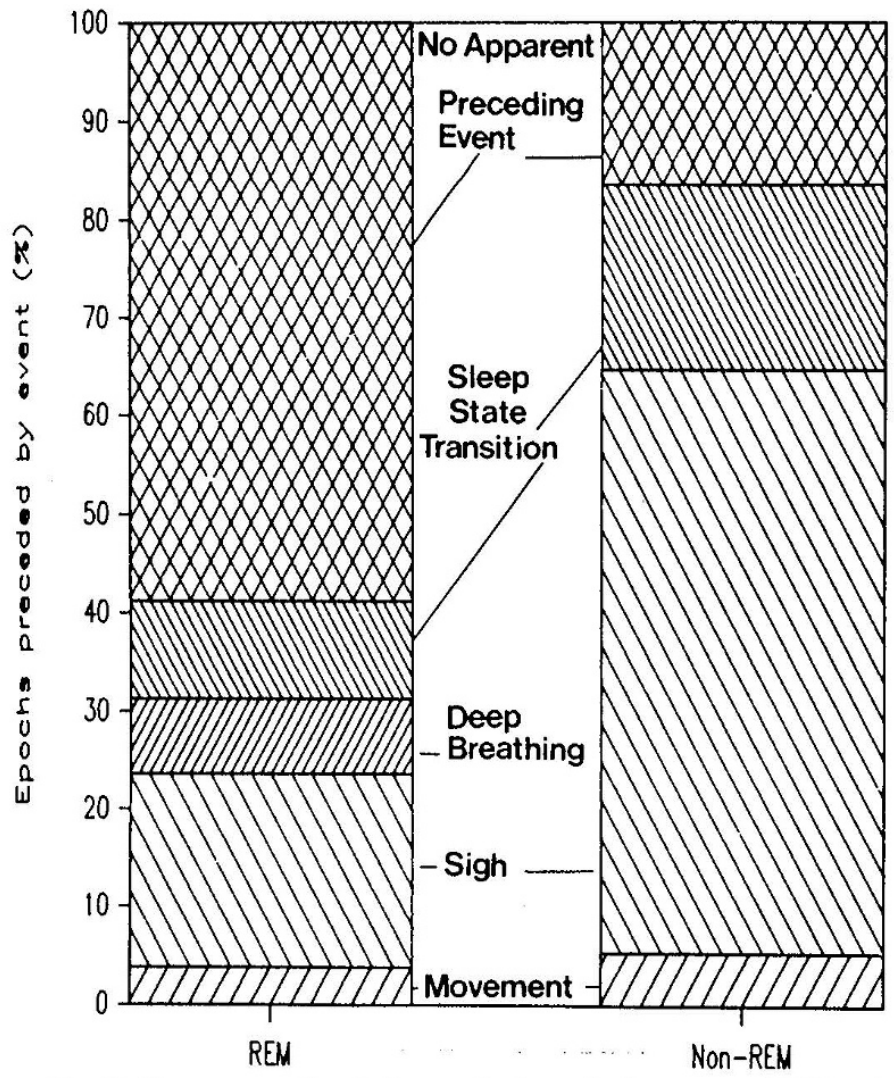

Fig. 2. Percentage of periodic epochs in each sleep state with identifiable preceding events. Significantly more of the non-REM epochs had identifiable precedents $(p<0.005)$.

epochs $(41 \%, 54$ of 131$)$ occurring during REM sleep were provoked by one of these factors, most having no recognizable preceding events (Fig. 2).

The periodic cycle duration decreased significantly with time, but was not different between sleep states, as revealed by twoway analysis of variance (Fig. 3: non-REM sleep $\mathrm{F}_{3,154}=12.8, p$ $<0.001$; REM sleep $\mathrm{F}_{3.709}=20.73, p<0.001$ ). Post hoc analysis demonstrated that the significant changes were between the $<1$ wk study and all later studies, in both sleep states, and between the 4- and 12-wk studies in non-REM. Pooling the data and performing an analysis with both sleep states combined did not make any substantive difference to these results, the overall means for " $C$ " for both sleep states combined were $15.0 \pm 3.6 \mathrm{~s}$ at $\langle 1 \mathrm{wk}$ of age, $13.1 \pm 2.9 \mathrm{~s}$ at $4 \mathrm{wk}, 12.2 \pm 2.2 \mathrm{~s}$ at $8 \mathrm{wk}$, and $12.4 \pm 1.8 \mathrm{~s}$ at $12 \mathrm{wk}$ of age. "C" was not significantly different between REM and non-REM at any postnatal age.

The coefficients of variation of both "B" (mean $35.6 \%$ ) and "A" $(29.8 \%)$ were much larger than the coefficient of variation of "C" $(15.66 \%)$. There was, therefore, no significant change in either " $A$ " or " $B$ " over the course of the study.

$\mathrm{TcPO}_{2}$ fell during $84 \%$ of the epochs, $81 \%$ of those occurring during non-REM and $85 \%$ of REM epochs $(p=N S)$. There was a highly significant overall fall in mean $\mathrm{TcPO}_{2}$ from a very variable mean of 66 torr prior to periodic breathing to a mean of 60.5 torr at the cessation of periodicity $(p<0.001)$. The fall in $\mathrm{TcPO}_{2}$ was significantly correlated with periodic epoch duration $(r=0.25, p<0.05)$. Obstructed breaths were not seen during periodic epochs in the inhospital studies.

\section{DISCUSSION}

There are two major findings of this longitudinal study of periodic breathing in healthy infants during normal spontaneous sleep. There is a progressive reduction in time duration of the

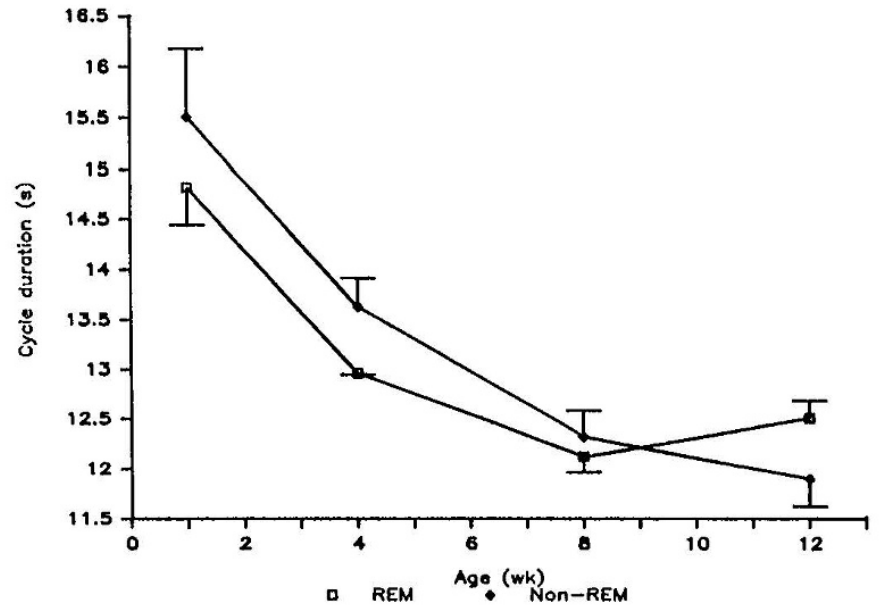

Fig. 3. Progressive change in periodic cycle duration over the first 12 wk of life, the differences between the first study (at $<1 \mathrm{wk}$ ) and all later studies were significant for both sleep states $(p<0.001)$. The difference between 4 and $12 \mathrm{wk}$ was significant $(p<0.05)$ for non-REM. Differences between sleep states were not significant.

periodic breathing cycle over the first 3 months of life which is independent of sleep state, and, in contrast, the factors which trigger periodic breathing appear to be sleep state dependent.

We recognize that behavioral definition of sleep state is not as precise as the use of EEG criteria. However, three of the four studies in each infant were performed in their own home at night in an effort to obtain records during natural sleep and avoid the need for medication, sleep deprivation, or change in environment. The recording of EEG was therefore impractical. Despite this, the incidence of periodic breathing in each sleep state was very similar to that reported by other investigators $(9,13)$. Furthermore the significant shortening of the periodic cycle was found to be independent of sleep state.

Periodic breathing was not associated with upper airways obstruction as has been previously reported in some premature infants (14). This suggests that differences exist in the mechanisms underlying periodicity at differing ages.

The precise cause of periodicity remains controversial, partly because there is no adequate animal model which will spontaneously exhibit periodic breathing. However, there is evidence to suggest that its occurrence may be due to instability in the respiratory control system and, more specifically, to an imbalance between the contributions of central and peripheral chemoreceptor drive $(3,4)$.

Periodicity is occasionally seen spontaneously during sleep in the healthy adult (15) and occurs more frequently at high altitude (16). The administration of hypoxic mixtures for a long enough period of time for the consequent hyperventilation to produce hypocapnia will produce periodicity in healthy adults (17).

The neonatal guinea pig and rabbit can be induced to exhibit periodicity by superfusion of the medulla with an alkaline fluid (1). In this model, the administration of carbon dioxide or the administration of oxygen will regularize the breathing pattern.

In an elegant experiment, Cherniack et al. (2) mechanically ventilated adult cats with a device which was driven by the animals' own phrenic nerve. They were able to induce periodicity by increasing the gain of the ventilator servo-controller, i.e. increasing the delivered tidal volume for a given degree of efferent phrenic nerve activity; this procedure lowered the $\mathrm{PaCO}_{2}$. The breathing pattern became regular after denervation of the carotid bodies, or their suppression with a high inspired oxygen fraction.

In each of these studies, the occurrence of periodicity appears to be related to a suppression of the central chemoreceptor, enhancement of peripheral chemoreceptor activity, or both (3, 4). The peripheral chemoreceptor is very rapidly responsive to 
changes in blood gases (18), without the damping inherent in the central mechanisms, and, therefore, when respiration is driven by the peripheral chemoreceptor, breathing patterns may be unstable. Theoretical models suggest that the major determinant of cycle duration during unstable, periodic breathing is likely to be the time delay within the alveolus/peripheral chemoreceptor/ respiratory muscle feed-back loop (4).

The factors within this feed-back loop that could be responsible for the maturation effect are a shortening in the alveolus to chemoreceptor circulation time; a decrease in the response time of the chemoreceptor or central integrative mechanisms; or an improvement in the efficiency of the respiratory pump causing a more rapid correction of the hypoxemia and hypercarbia associated with the apneic pause.

There is sufficient evidence at present to support only one of these possibilities, a maturational reduction in the response time of the peripheral chemoreceptor itself. Belenky et al. (9), in the unanesthetized newborn lamb, demonstrated a progressive postnatal decrease in the delay which occurs between the time an hypoxic stimulus reaches the peripheral chemoreceptor and the appearance of hyperpnea. The reduction in periodicity cycle duration in the human infant may, therefore, be related to a reduction in carotid body response time. Further evidence to support a maturational change in chemoreceptor function comes from histochemical studies in rats which have shown a reduction in the catecholamine content of the carotid body over the first 16 days of life (19). The catecholamines, and in particular, dopamine, act as transmitters within the carotid body with a primarily inhibitory function (20).

Some investigators (21) have suggested that the percentage of time spent breathing periodically is an indicator that an infant is at risk of dying from sudden infant death syndrome. Other investigators have been unable to substantiate this $(22,23)$ and have stressed the variability in the incidence and duration of periodicity in normal infants $(8,13,24)$. Our results suggest an increase in the percentage of time spent breathing periodically from the 1st to the 4th wk of life, and a progressive decrease thereafter. The low incidence of periodicity in the immediate postnatal period, with a greater incidence at about 1 month, has been noted previously $(7,8,25)$. Our hypothesis would suggest that this is due to the relative inactivity of the peripheral chemoreceptor at this time, when it is believed that a "resetting" of the chemoreceptor to the higher oxygen extrauterine environment is occurring (26). The progressive reduction in the incidence of periodicity after the 4th wk is, we presume, a feature of the maturing stability of the respiratory control system (27).

We have observed that periodic breathing in non-REM sleep is more frequently preceded by spontaneous sighs or a change of sleep state. Although it has been previously observed that periodicity "usually" follows a sigh (8), the sleep state dependency of this observation has not previously been reported. A sigh will transiently lower arterial $\mathrm{PCO}_{2}(28)$ and has been shown to consistently destabilize respiration in the newborn infant, even when overt periodicity is not induced (26). The sudden withdrawl of behavioral drive in the transition from REM to non-REM, probably has a similar effect. State changes, therefore, appear to have a profound influence on stability, and thus on the prevalence of periodic breathing. However, the mechanisms underlying the duration of the periodic cycle appear, from the data produced in the current study, to be independent of sleep state.

Bureau et al. (29) have demonstrated the importance of the peripheral chemoreceptor in the maturation of postnatal breathing patterns and have noted a tendency for lambs with denervated carotid bodies to die suddenly and unexpectedly during the first few weeks of postnatal life. It has also been reported that carotid body denervated dogs may fail to arouse during hypoxia (30) or airway obstruction (31). Furthermore, one report (32) describes a much higher dopamine content of the carotid bodies of children dying of sudden infant death syndrome suggesting a lack of the usual postnatal fall in dopaminergic inhibition of the peripheral chemoreceptor $(18,33)$ in these children. The investigation of peripheral chemoreceptor function in children at risk of dying from sudden infant death syndrome has been hampered in the past by the lack of a noninvasive method to study this aspect of respiratory control.

The previously unreported progressive reduction of the periodic cycle duration over the first $12 \mathrm{wk}$ of life may be an indicator of the maturation of the peripheral chemoreceptor. The periodic cycle duration may be a sensitive noninvasive tool for evaluation of the role of the peripheral chemoreceptor in the maturation of the control of breathing in the young human infant. Further studies to correlate peripheral chemoreceptor function and periodic breathing patterns are required.

\section{REFERENCES}

1. Wennergren G, Wennergren M 1983 Neonatal breathing control mediated by the central chemoreceptors. Acta Physiol Scand 119:139-146

2. Cherniack NS, Von Euler C, Homma I, Kao FF 1979 Experimentally induced Cheyne-Stokes breathing. Respir Physiol 37:185-200

3. Cherniack NS, Longobardo GS 1973 Cheyne-Stokes breathing-an instability in physiologic control. N Engl J Med 288:952-957

4. Khoo MCK, Kronauer RE, Strohl KP, Slutsky AS 1982 Factors influencing periodic breathing in humans: a general model. J Appl Physiol 53:644-659

5. Franks CI, Watson JBG, Brown BH, Foster EF 1980 Respiratory patterns and risk of sudden unexpected death in infancy. Arch Dis Child 55:595-599

6. Waite SP, Thoman EB 1982 Periodic apnea in the full-term infant: individual consistency, sex differences and state specificity. Pediatrics 70:79-86

7. Hunt CE, Brouillette RT, Hanson D, David RJ, Stein IM, Weissbluth M 1985 Home pneumograms in normal infants. J Pediatr 106:551-555

8. Carse EA, Wilkinson AR, Whyte PL, Henderson-Smart DJ, Johnson P 1981 Oxygen and carbon dioxide tensions, breathing and heart rate in normal infants during the first six months of life. J Dev Physiol 3:85-100

9. Belenky DA, Standaert TA, Woodrum DE 1979 Maturation of hypoxic ventilatory response of the newborn lamb. J Appl Physiol 47:927-930

10. Booth CL, Leonard HL, Thoman EB 1980 Sleep states and behaviour pattern in preterm and fullterm infants. Neuropediatrics 11:354-364

11. Kelly DH, Walker AM, Cahen L, Shannon DC 1980 Periodic breathing in siblings of sudden infant death syndrome. Pediatrics 66:515-520

12. Snedecor GW, Cochrane WG 1980 Statistical Methods, 7th ed. Iowa State University Press, Ames, IA

13. Hoppenbrouwers T, Hodgman JE, Harper RM, Hofman E, Sterman MB McGinty DJ 1977 Polygraphic studies of normal infants during the first six months of life. III. Incidence of apnea and periodic breathing. Pediatrics 60:418-425

14. Miller MJ, Carlo WA, DiFiore J, Martin RJ 1986 Airway obstruction occurs during periodic breathing in premature infants. Pediatr Res 20:436A (abstr)

15. Specht $\mathrm{H}$, Fruhmann $\mathrm{G} 1972$ Incidence of periodic breathing in 2000 subjects without pulmonary or neurological disease. Bull Physiol Pathol Respir 8:1075

16. Reite M, Jackson D, Cahoon RL, Weil JV 1975 Sleep physiology at high altitude. Electroenceph Clin Neurophysiol 38:463

17. Berssenbrugge A, Dempsey J, lber C, Skatrud J, Wilson P 1983 Mechanisms of hypoxia induced periodic breathing during sleep in humans. J Physio 343:507-524

18. McQueen DS, Pallot DJ 1983 Peripheral arterial chemoreceptors. In: Pallot DJ (ed) Control of Respiration. Oxford University Press Inc, New York

19. Hervonen A, Kanerva L, Korkala O, Paranen S 1972 Effects of hypoxia and glucocorticoids on the histochemically demonstrable catecholamiens of the newborn rat carotid body. Acta Physiol Scand 86:109-114

20. Zapata $P 1977$ Modulatory role of dopamine on arterial chemoreceptors. Adv Biochem Psychopharmacol 16:291-298

21. Kelly DH, Shannon DC 1979 Periodic breathing in infants with near-miss sudden infant death syndrome. Pediatrics 63:355-360

22. Guilleminault C, Ariagno R, Korobkin R, Nagel L, Baldwin R, Coons S, Owen M 1979 Mixed and Obstructive sleep apnea and near-miss for sudden infant death syndrome 2. Comparison of near miss and normal control infants by age. Pediatrics 64:882-891

23. Hodgman J, Hoppenbrouwers T, Geidel S, Hadeed A, Sterman MB, Harper R, McGinty D 1982 Respiratory behaviour in near-miss sudden infant death syndrome. Pediatrics 69:785-792

24. Ellingson RJ, Peters JF, Nelson B 1982 Respiratory pauses and apnea during daytime sleep in normal infants during the first year of life: longitudinal observations. Electroenceph Clin Neurophysiol 53:48-59

25. Stein IM, Fallo M, Merisalo RL, Kennedy JL 1983 The frequency of apnea and bradycardia in a population of healthy normal infants. Neoropediatrics 14:73-75

26. Blanco CE, Dawes GS, Hanson MA, McCooke HB 1982 The arterial chemoreceptors in fetal sheep and newborn lams. J Physiol 330:38P

27. Fleming PJ, Goncalves AL, Levine MR, Woollard S 1984 The development of stability of respiration in human infants: changes in ventilatory responses to spontaneous sighs. J Physiol 347:1-16

28. Lewis G, Ponte J, Purves MJ 1980 Fluctuations of $\mathrm{PaCO} 2$ with the same period as respiration in the cat. J Physiol 298:1-11 
29. Bureau MA, Lamarche J, Foulon P, Dalle D 1985 Postnatal maturation of respiration in intact and carotid body denervated lambs. J Appl Physiol 59:869-874

30. Bowes G, Townsend ER, Kozar LF, Bromley SM, Phillipson EA 1981 Effect of carotid body denervation on arousal response to hypoxia in sleeping dogs. J Appl Physiol 51:40-45

31. Bowes G, Townsend ER, Bromley SM, Kozar LF, Phillipson EA 1981 Role of the carotid body and of afferent vagal stimuli in the arousal response to airway occlusion in sleeping dogs. Am Rev Respir Dis 123:644-647

32. Perrin DG, Cutz E, Becker LE, Bryan AC, Madapallimatum A, Sole MJ 1984 Sudden infant death syndrome: increased carotid body dopamine and noradrenaline content. Lancet 2:535-537

33. Mayock DE, Standaert TA, Guthrie RD, Woodrum DE 1983 Dopamine and carotid body function in the newborn lamb. J Appl Physiol 54:814-820 